\title{
Odor objects in a complex world
}

\author{
Shannon B Olsson \\ From 1st International Workshop on Odor Spaces \\ Hannover, Germany. 4-7 September 2013
}

Every decision an animal makes is the result of the brain's complex processing of input from the environment to produce a specific neural output. Yet, the world is a cacophony of information. How, then, has the nervous system evolved to sort through this massive influx of data and reach a particular outcome? Our research explores how complex sensory information can lead to decision making in one of nature's most efficient "microbrains": the insect. To locate an odor source, an olfactory system must be able to simultaneously discriminate both the identity and location of the odor source from a noisy chemical background. Flying insects, in particular, have tremendous capabilities to localize odor sources while challenged by the high-speed performance of flight. We find that insects make olfactory decisions through stepwise spatiotemporal feature extraction of complex "odor objects" from the antenna to the brain. Our work in moths suggests that complex odors can be considered "objects" in much the same way we consider objects as composite images in the visual sense. The sensory repertoire of the antenna acts as a filter for ecologically-relevant information, while the antennal lobe of the moth brain extracts odor objects from multicomponent chemical blends. Our work in Drosophila melanogaster also finds that the signal transduction cascades of insect sensory neurons are ideally suited to localize turbulent odor object plumes during flight. Finally, our comparative analyses across species also imply that insects have evolved to define odor objects at different levels of the brain depending on their ecological niche. Taken together, these analyses provide both mechanistic insight as well as an experimental database to understand how flying insects have evolved to make decisions in a complex natural odor space.

Published: 16 April 2014

Dept. Evolutionary Neuroethology, Max Planck Institute for Chemical Ecology, Jena, Germany

C Biomed Central

C 2014 Olsson: licensee BioMed Central Ltd. This is an Open Access article distributed under the terms of the Creative Commons Attribution License (http://creativecommons.org/licenses/by/2.0), which permits unrestricted use, distribution, and reproduction in any medium, provided the original work is properly cited. The Creative Commons Public Domain Dedication waiver (http:// creativecommons.org/publicdomain/zero/1.0/) applies to the data made available in this article, unless otherwise stated.
doi:10.1186/2044-7248-3-S1-O22

Cite this article as: Olsson: Odor objects in a complex world. Flavour

2014 3(Suppl 1):022.

Submit your next manuscript to BioMed Central and take full advantage of:

- Convenient online submission

- Thorough peer review

- No space constraints or color figure charges

- Immediate publication on acceptance

- Inclusion in PubMed, CAS, Scopus and Google Scholar

- Research which is freely available for redistribution Submit your manuscript at
www.biomedcentral.com/submit C BioMed Central 